\title{
Instrumentos de análisis para caracterizar el comportamiento discursivo de la deixis espacial en relatos conversacionales.
}

\section{Analysis instruments to characterize the discursive behavior of spatial deixis in conversational stories.}

\author{
Leisy Tania Ulloa Casaña \\ Departamento de Letras / Universidad de Oriente (CUBA) \\ CE: tania@uo.edu.cu ID ORCID: 0000-0002-0493-2345
}

DOI: $10.32870 /$ sincronia.axxiii.n76.23b19

Esta obra está bajo una Licencia Creative Commons Atribución-NoComercial 4.0 Internacional

Recibido: $20 / 03 / 2019$

Revisado: 09/05/2019

Aprobado: 12/06/2019

\section{RESUMEN}

En este artículo se propone cómo caracterizar el comportamiento discursivo de la deixis espacial en relatos conversacionales a partir de la consideración de tres planos que favorecen el proceso de análisis de la deixis como fenómeno lingüístico. Esta propuesta responde a la necesidad de realizar un estudio donde se muestre la estrecha relación entre el lenguaje, la situación comunicativa donde es producido y el tipo de texto que es analizado.

Palabras clave: Deixis espacial, relatos conversacionales, pragmática, comportamiento discursivo.

\section{Abstract:}

In this research it is proposed a characterization of the place deixis discursive behavior into conversational speeches. This characterization can be made through the consideration of there levels 
which are very useful in the analysis process of deixis as a linguistic phenomenon. This proposal answers to the need of making a research in which the relation among language, the communicative situation in which it is produced and the text to be analyzed can be shown.

Keywords: Place deixis, conversational speeches, discursive behavior, pragmatics.

\section{Introducción}

En toda investigación resulta indispensable explicar qué decisiones metodológicas se han adoptado para examinar los datos seleccionados, por tal razón, en este artículo se presenta una aportación teórico-metodológica para un análisis posterior que permita caracterizar el comportamiento discursivo de la deixis espacial en relatos conversacionales; para tal empeño, se precisa de una propuesta que permita estudiar la estructura que involucra todas las propiedades de la situación que son relevantes en la producción y comprensión de estos textos.

Es necesario resaltar que los fragmentos utilizados para la ejemplificación en el presente artículo pertenecen a un corpus oral de hablantes de la ciudad de Santiago de Cuba, previamente analizado, lo que ha permitido considerar cómo se articulan las formas lingüísticas en uso junto a elementos de carácter extralingüístico en la interacción social.

Puesto que los deícticos son percibidos como "indicios" que adquieren valores distintos a partir de la situación comunicativa donde son empleados resulta necesario diseñar procedimientos de comprensión y análisis para sistematizar las observaciones realizadas sobre su comportamiento en una muestra seleccionada para establecer, de este modo, qué es lo genuino, regular y eficaz comunicativamente.

\section{La deixis espacial. Sus unidades.}

Una primera distinción básica entre las unidades deícticas se relaciona con el tipo de información deíctica. Desde este punto de vista, la deixis espacial codifica las referencias locativas de los 
enunciados en relación con la situación y orientación física de los participantes en el acto de habla (Escavy, 2008, p. 70).

Desempeñan esta función, en la lengua española, los pronombres demostrativos, los adverbios demostrativos de lugar, los verbos deícticos y otras expresiones con significado deícticoespacial entre ellas adverbios nominales transitivos e intransitivos, determinadas frases preposicionales locativas y algunos sustantivos y adjetivos.

Los pronombres demostrativos constituyen un paradigma ternario cerrado -este, ese aquelque manifiesta una variación genérica triple -masculino, femenino y neutro- y numérica doble singular y plural. Son los encargados de situar en las coordenadas espaciales las entidades referidas por los sustantivos a los que determinan o sustituyen (Hipogrosso, 2001, p. 2); se convierten en índices que indican el objeto desde el punto de origen del hablante, por lo que desarrollan una dimensión deíctica espacial articulada sobre la dimensión personal, constituyendo, de esta forma, los representantes más característicos del paradigma de las categorías deícticas (Eguren, 2000, p. 927).

Los adverbios demostrativos de lugar en la lengua española constituyen un reducido grupo de unidades lingüísticas ${ }^{1}$ (aquí, ahí, allí, acá y allá) morfológicamente invariables cuya función más habitual es la de complemento circunstancial o adjunto de un verbo (Eguren, 2000, p. 955). Esta clase de adverbios ha sido etiquetada de maneras distintas (pronominales o deícticos) resaltando, en cada caso, diversos aspectos de su semántica o sintaxis.

Se organizan en dos subsistemas, uno ternario (aquí, ahí, allí) y otro binario (acá, allá). El primero manifiesta un evidente paralelismo con el sistema de pronombres demostrativos (esteaquí, ese-ahí, aquel-alli) y como estos, establece tres grados de distancia. El otro postula una relación binaria (acá, allá) y expresa proximidad o lejanía relativas con respecto al lugar en el que se encuentra el hablante (Eguren, 2000, p. 958).

\footnotetext{
${ }^{1}$ Son también adverbios demostrativos en lengua española los de tiempo (ahora, entonces, hoy, ayer, mañana, anoche), de cantidad o grado (así, tanto) y de manera (asi) (RAE, 2009, p. 1311).
} 
La denominación de verbos deícticos, por su parte, se basa en la oposición esencial entre posición estática y dinámica - reposo o movimiento. Cifuentes Honrubia (1989, p. 59) observa que su conceptualización no es sino una categorización de las relaciones físicas en términos gramaticales. La localización se fundamenta en la ubicación espacial de los participantes del acto comunicativo mientras el movimiento describe una trayectoria poniendo en relación un punto de observación también vinculado con esa propia posición.

Sus valores deíctico-referenciales permiten reunirlos en dos grupos:

- Los que expresan cambio de localización (por eso son también denominados verbos de movimiento) en los que no solo se conceptualiza la trayectoria, sino que puede aparecer focalizada en uno de sus puntos (origen, trayecto, meta) como entrar, salir, ir, venir, llegar, bajar, subir, regresar, traer, llevar, volver.

- Los que focalizan el espacio de localización como estar, situar.

Existen casos como "emigrar, exportar, importar" que pudieran considerarse verbos deícticos si se atiende, por ejemplo, al hecho de que emigrar, supone un desplazamiento a un lugar siempre distinto de la localización propia (normalmente limitada al país) de quien lo enuncia, especificando, de esta forma, la situación espacial concreta de la situación comunicativa.

Las expresiones deícticas de carácter espacial, distintas de los adverbios demostrativos pueden clasificarse, según su naturaleza categorial, en dos grupos (Eguren, 2000, p. 967).

- Adverbios nominales ${ }^{2}$ : Transitivos.

Intransitivos.

- Frases preposicionales locativas con significado deíctico.

El grupo de adverbios nominales transitivos "encima, debajo, delante, detrás, dentro, fuera, enfrente, alrededor, cerca y lejos" es, básicamente, no deíctico, pues fija un eje de referencia

\footnotetext{
${ }^{2}$ Se les ha asignado esta denominación pues los adverbios nominales aunque poseen características que los relacionan con las preposiciones se vinculan, en otros casos, con el nombre (Eguren, 2000, p. 600).
} 
espacial distinto al de las variables deícticas "dentro de la casa; enfrente del museo; lejos de Santiago de Cuba"; en ocasiones, sin embargo, puede usarse de manera deíctica en los casos en que se omite el complemento, este fenómeno se conoce como deixis por defecto (Fillmore, 1975). Así "quédate fuera, siéntense alrededor, ponlo delante" pueden interpretarse como "fuera, alrededor o delante" de donde se encuentra el que emite dichos enunciados.

De igual forma, se obtiene lectura deíctica cuando estos adverbios participan en construcciones con sustantivos que no pueden establecer una localización inherente ${ }^{3}$ debido a sus peculiares características físicas; "siéntate detrás de la mesa" designa un lugar opuesto a aquel en el que se encuentra el hablante pues las mesas no poseen parte delantera o trasera, como sí tendría, por ejemplo, una silla. Conviene entonces diferenciar las unidades con sentido deíctico, de las unidades susceptibles de un uso deíctico.

Los adverbios nominales intransitivos "arriba, abajo, adelante, atrás, adentro y afuera" a diferencia de los primeros, son de naturaleza básicamente deíctica, pues para su interpretación se adopta una perspectiva localizadora subjetiva; cuando digo "sube arriba o mi hermano vive abajo" se identifican lugares en relación con el sitio en el que se halla el hablante (Eguren, 2000, p. 968).

Las frases preposicionales con significado deíctico, por su parte, son aquellas que tienen una base combinatoria de preposición(es) con otras clases de palabras, fundamentalmente adverbios y sustantivos (Cifuentes, 1989, p. 273). En estas construcciones, la preposición desempeña la función de nexo o conector entre los elementos que intervienen en el proceso de localización; son empleadas para señalar multitud de matices y caracterizaciones espaciales. El desplazamiento, por ejemplo, se hace explícito con el uso de la preposición (a); la procedencia con (de); la localización con (en), mientras que (para) indica la orientación direccional.

Estas expresiones, por lo general, son referenciales no deícticas "desde Holguín; sobre el estante; en la universidad", sin embargo, existen casos de deixis por defecto debido a la ausencia de complementos que marquen puntos de referencia "colócate a la izquierda; Holguín está a 200

\footnotetext{
${ }^{3}$ En la perspectiva inherente lo que sirve como punto de referencia para la localización espacial es una determinada dimensión o cara del objeto localizante o base (Cifuentes, 1989, p. 99).
} 
kilómetros; la universidad está al norte", o sea, "a la izquierda; a 200 kilómetros; al norte" del lugar donde se encuentra la persona que produce el enunciado.

Pueden mencionarse, por otro lado, determinados adjetivos como "norteño, occidental, oriental, superior, inferior" (Real Academia Española, 2009, p. 1276) que contienen información deíctica espacial porque los contextos en que aparecen pueden designar individuos diferentes en función del lugar donde se empleen. Por ejemplo, el adjetivo superior, no tiene valor espacial en "ella era muy superior a él", en cambio sí lo tiene en "mi oficina está en el piso superior", o sea, superior con relación al piso en el que estoy ahora.

El significado de los sustantivos "extranjero, forastero y nativo" se puede interpretar también de manera deíctica. La referencia de la expresión "los ciudadanos extranjeros" puede ser distinta si la empleamos, por ejemplo, en Cuba o Venezuela; el punto de referencia puede formar parte del discurso y proporcionarse en un fragmento anterior o posterior del texto "Al evento asistieron ponentes cubanos y extranjeros; España fue el único país invitado".

La utilización de los deícticos en los enunciados permite comprender que, justamente, una de sus funciones es, sin dudas, la de marcar en toda situación de habla el lugar de producción de la palabra). Estas señalizaciones explícitas al emplazamiento físico dan cuenta de la variación que se produce en su empleo de acuerdo con condicionamientos espacio-temporales, los cuales ofrecen las razones por las que un hablante elige unas expresiones frente a otras, constreñido, además, por las exigencias del tipo de texto en particular.

\section{Los relatos conversacionales.}

En el desenvolvimiento histórico de las diferentes culturas, "narrar" es una forma de comunicación y simbolización propia de los seres humanos, en cuyo tratamiento confluyen diversas problemáticas (socio-culturales, psicológicas y lingüísticas) que permiten concebirla como una capacidad derivada del lenguaje (Gutiérrez, 2001). Desde una perspectiva socio-discursiva las narraciones orales, son 
consideradas producciones textuales situadas en las que se integran el plano lingüístico, el textual o enunciativo y el situacional o social (García, 2010) ${ }^{4}$.

El concepto de historia (narración o relato) referido a "contar cosas" que han pasado, aparece señalada, por ejemplo, en autores como V. Dijk (lo que nos pasó...recientemente o hace tiempo), Polanyi (specific post-time events), o W. Labov (sucesión de cláusulas y secuencia de eventos que es posible inferir ocurrieron en la realidad) (Apud.Shiro, 1999, p. 15).

B. Gallardo (1996) y el Grupo Val.Es.Co (2000), por su parte, denominan relato conversacional o secuencia de historia a un tipo de microestructuras narrativas que se suceden a lo largo de una conversación en las que el hablante monopoliza la palabra para "contar algo" que tiene un valor social concreto y donde el resto de los participantes quedan relegados al sistema secundario de la toma de turno; deben ser interesantes como historia para que sea legítima su inclusión en la conversación, cumpliendo, de esta forma, con el criterio de interés.

A partir de lo expuesto, se asume, para esta investigación, la definición de relato conversacional como una narración de tipo oral que representa un evento a partir del desarrollo tempo-espacial de los acontecimientos ocurridos. Los relatos conversacionales forman parte del proceso mediante el cual el sujeto se construye en sociedad y construye al mismo tiempo su realidad por lo que su presencia atiende al contexto en que aparecen y están configurados por el entorno físico donde se producen; en ellos los hablantes cuentan sus vivencias, justifican sus ideas o, incluso, apoyan los argumentos del interlocutor.

Resulta importante destacar que al recapitular la experiencia pasada, los hablantes tienen que re-acordar lo narrado, en el sentido de que se mantengan inalterables los hechos contados en cuanto a cómo ocurrieron en la realidad, pues deben ajustarse, en cada caso, a las necesidades temáticas de la conversación en que aparecen y al espacio en que se producen (piénsese, por ejemplo, en los relatos contados más de una vez en contextos diferentes).

\footnotetext{
${ }^{4}$ En otros casos, se reserva el término narración oral para los textos que responden a rasgos culturales de la región de origen que son resultado de una tradición oral que perdura con el paso de los años (Castillo y Camacho, 2007, p. 32).
} 
Para caracterizar la estructura de los relatos conversacionales, se acudirá, primeramente, a la propuesta de W. Labov (1972), por considerar que es un trabajo clásico que ha tenido considerable impacto y sigue teniendo vigencia en el análisis de este tipo de discurso. Este autor sostiene que una narración completa o prototípica consta de varias secciones, cada una de las cuales puede considerarse la respuesta a una pregunta subyacente, con excepción de la coda, por su naturaleza de cláusula libre:

- Resumen (¿De qué trata?)

- Orientación (¿Quién, cuándo, qué, dónde?)

- Complicación (¿Qué sucedió después?)

- Resolución (¿Qué es lo que finalmente ocurrió?)

- Evaluación (¿Por qué/para qué lo cuentas?)

- Coda.

Sin embargo, este modelo no es el único presentado por los estudiosos de la estructura del relato. Existen otras propuestas, como la de B. Gallardo (1986) en la que se reduce a tres partes: prólogo + historia + evaluación. El prólogo asegura la posesión del turno y se emplea para adelantar aspectos informativos relacionados con los sucesos referidos; en la historia aparecen los elementos que la configuran de manera que resulte evidente su vinculación con el habla en curso y la evaluación presenta las consecuencias "morales" que se derivan de lo contado.

Aunque los modelos presentados no difieren en su totalidad, se propone, con el fin de lograr mayor precisión en la descripción de la estructura de los relatos conversacionales analizados, las siguientes partes: situación inicial u orientación, nudo o complicación, resolución o situación final y evaluación.

La situación inicial define el tema o punto de la historia e identifica el tiempo y lugar donde sucedieron los hechos que se cuentan; en el nudo o complicación se narran los eventos centrales, en esta parte, puede producirse, además, una vuelta al tiempo de la conversación que supone una 
interrupción temporal de lo narrado, la cual se relaciona con el objetivo argumental del relato en cuestión.

La resolución o situación final señala a los interlocutores el término del relato conversacional por lo que suele ser frecuente la presencia de deícticos temporales que permiten distinguir claramente dos planos de la enunciación diferentes: el de la historia y el de la situación comunicativa. En esta parte, es común, además, la presencia de marcadores discursivos ${ }^{5}$, los cuales incitan al receptor a construir un tipo de relación semántica particular entre dos eventos. Por último, la evaluación, que puede o no, estar presente, se relaciona con el valor argumental que adquiere el relato en el marco de la interacción discursiva de la que forma parte, pues hace referencia al sentido emocional y social que para el hablante tienen los hechos contados, razón por la cual se sistematiza pragmáticamente desde el ahora, forma textual clave que señala el momento enunciativo.

\section{Propuesta de análisis.}

La consideración de las características que distinguen el objeto de estudio, en este caso, permitió concebir el análisis a partir de tres planos, los cuales ofrecen importantes instrumentos que aseguran el proceso de análisis de la deixis como fenómeno lingüístico en relatos conversacionales. Esta propuesta responde a la necesidad de realizar un estudio donde se muestre la estrecha relación entre el lenguaje, la situación comunicativa donde es producido y el tipo de texto que es analizado:

- Plano de la tipología: el relato conversacional como tipo de texto.

- Plano del componente lingüístico: la localización espacial.

- Plano del componente pragmático: la adecuación contextual del significado.

\footnotetext{
${ }^{5}$ Se entienden como palabras de clase cerrada que funcionan como un "pegamento semántico" entre diversas unidades lingüísticas del discurso, las cuales operan como instrucciones de procesamiento que indican al lector u oyente cómo debe integrar dos unidades predicativas (Arnás y Fumero, 2007, p. 5).
} 
El primer plano (denominado plano de la tipología) corresponde al relato conversacional; en él se atiende al despliegue de relaciones espaciales que posibilitan la ubicación de los elementos implicados en la enunciación a partir de las características propias de este tipo de texto. El segundo, el del componente lingüístico, permite estudiar las categorías que cumplen la función de referencia deíctica, las cuales se convierten en indicios que pueden remitir tanto a elementos del enunciado (intratextuales) como al acto de enunciación (extratextuales).

El plano del componente pragmático tiene en cuenta, por su parte, las particularidades de los deícticos espaciales derivadas de la situación en que aparecen. Además del significado o sentido que el texto comporta en sí mismo, se establece una peculiar relación con sus usuarios, los cuales, en la mayoría de las ocasiones, aportan nuevos elementos de significación intencional; como bien expresara J. Portolés (s.f.), todo discurso se compone de una parte puramente gramatical y de otra pragmática, obtenida gracias al contexto.

\section{1 Plano de la tipología: el relato conversacional como tipo de texto}

Los relatos conversacionales constituyen una clase de texto oral con características peculiares en el que los deícticos espaciales pueden señalar, tanto lugares de la realidad extralingüística que se encuentran inmediatos a la situación comunicativa del acto de habla o puede el hablante trasladar al receptor, en otros casos, a un campo perceptivo distinto de la posición ocupada por ambos en el momento de la enunciación; de ahí que elementos como la estructura de los relatos, los puntos de referencias asumidos para lo narrado, así como la codificación temporal de las acciones presentadas, sean aspectos que necesiten atenderse en una investigación de esta naturaleza.

Para describir el comportamiento de la deixis espacial en estos textos, el análisis debe partir de la explicación del funcionamiento discursivo de estas expresiones teniendo en cuenta su aparición en las partes que constituyen los relatos (situación inicial u orientación, nudo o complicación, resolución o situación final y evaluación) pues existe una diferenciación funcional en cada una de ellas que repercute en el empleo de las expresiones deícticas estudiadas. 
En este sentido, la orientación y complicación, por ejemplo, tienen funciones macroestructurales diferentes; en la primera se presentan los referentes, en la segunda, se suceden los acontecimientos. Las estrategias sintácticas específicas de cada segmento varían: la orientación se formula en oraciones "presentadoras de estados", mediante la inclusión, en nuevas unidades de entonación, de informaciones relacionadas con el área de identificabilidad del referente (una vez aquí, antes en este sitio...); mientras que la complicación requiere oraciones "presentadoras de acciones", en las cuales el verbo es el encargado de aportar información (subían por aquí, salieron de este lugar).

El siguiente cuadro resulta de utilidad pues permite mostrar la ubicación de los deícticos espaciales en las partes que conforman la estructura del relato conversacional y derivar, a partir de la posición, sus funciones discursivas (Tabla 1).

Tabla 1

\begin{tabular}{|c|c|}
\hline Estr & \\
\hline $\begin{array}{l}\text { Situación Inicial. } \\
\text { Orientación. }\end{array}$ & $\begin{array}{l}\text { Siempre he escuchado anécdotas referidas a este barrio/ decían que } \\
\text { aquí se vendía cuajo y ubre/ }\end{array}$ \\
\hline $\begin{array}{l}\text { Nudo, complicación, } \\
\text { tensión. }\end{array}$ & $\begin{array}{l}\text { eso es parte de la res que se freía como chicharrones y se vendía a un } \\
\text { centavo y dos centavos y demás y era una comida podíamos decir } \\
\text { propia del barrio// podría hablar de los amigos que se reunieron aquí e } \\
\text { hicieron un club a Guillermón Moncada y se reunían aquí/ hacían } \\
\text { tertulias/ hacían cuentos/ vinieron de Moncada donde tenía el Partido } \\
\text { Popular su sede/ estaba Blas Roca/ se comentaba que se hacían las } \\
\text { grandes tertulias políticas que tuvieron un peso importante para el } \\
\text { futuro de la Revolución// las personas de Los Hoyos tienen sentido de } \\
\text { pertenencia// }\end{array}$ \\
\hline $\begin{array}{l}\text { Resolución, Situación } \\
\text { final. }\end{array}$ & $\begin{array}{l}\text { ellos siempre han tratado de ser los primeros/ siempre han tenido su } \\
\text { afán de ser los primeros/ de ser los mejores y se han preparado en este }\end{array}$ \\
\hline
\end{tabular}




\begin{tabular}{|l|l|} 
& barrio para ello \\
\hline Evaluación. & $\begin{array}{l}\text { y no es que me excluya / los negros de Los Hoyos somos egoístas y no } \\
\text { pensamos que ninguna conga/ ningún paseo que no sea de aquí de Los } \\
\text { Hoyos/ puede tener el primer lugar/ nosotros tenemos que ser los } \\
\text { primeros porque decimos que somos los fundadores de lo que es la } \\
\text { conga/ de lo que es la vida del carnaval. }\end{array}$ \\
\hline
\end{tabular}

Debe considerarse, por otro lado, el hecho de que en este texto en particular, los hablantes tienen la posibilidad de transferir el centro deíctico a una situación espacio-temporal distinta a la de su enunciación, por lo que pueden señalarse lugares no necesariamente circunscritos a la vista inmediata o al ámbito que rodea a los interlocutores; los referentes, por tanto, están en correspondencia con el tema del relato conversacional en cuestión.

Desde los presupuestos de la enunciación, el yo-aquí-ahora constituye el "centro deíctico" o "punto cero" de las coordenadas contextuales para la realización e interpretación de los enunciados; justamente los términos deícticos son las unidades lingüísticas que los relacionan con la situación en que son emitidos, al anclarlos al entorno en que la comunicación se produce; este sistema como bien afirmara K. Bühler (1934) no es inamovible, sino desplazable y manipulable.

Estas reflexiones permiten afirmar que en los relatos conversacionales no solo es posible hacer alusión a elementos perceptibles en el entorno sensible inmediato del hablante sino que puede cambiar de posición el punto de referencia utilizado hacia uno virtual, proyectado por el discurso, que carece, incluso, de una base material significada (Stanzel, 1978) (Esquema 1).

Esquema 1. Puntos de referencia en relatos conversacionales.

Punto de origen

Origo (yo, aquí, ahora)

\section{,}

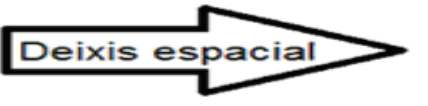

Punto de referencia

Elementos de la situación pertenecientes al espacio enunciativo. 

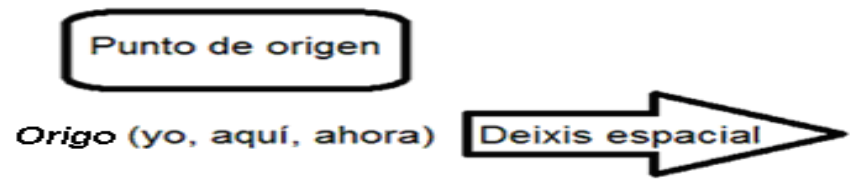

Punto de

referencia

Elementos de la situación

en relación con el punto de referencia establecido.

Fuente: Elaboración propia.

En tales circunstancias, conviene advertir que el lugar en que se desarrolla la historia puede coincidir con el punto en el que se encuentra el emisor en el momento de su producción; en estos casos, la proximidad es la condición más simple de esta estructuración perceptiva (todo aquello que es posible ver) y al igual que las otras relaciones topológicas, tiene un papel primordial en la organización espacial. La zona a la cual se refiere el hablante es identificable y generalmente bien circunscrita a la situación comunicativa que se describe.

La mostración deíctica tiene lugar de forma directa y suele ser acompañada de marcas suprasegmentales, así como gestos y ademanes que colaboran en la atribución de la identidad o ubicación del referente, pues dirigen la atención del oyente hacia el punto que se desee destacar. El hablante es el centro de toda la exposición y de él se desprende la significación deíctica, al tenerse en cuenta los parámetros constitutivos de la situación que hacen referencia al horizonte visual de su enunciador.

El siguiente esquema muestra la localización y orientación espacio-temporal en el tipo de mostración antes descrita (Esquema 2).

Esquema 2. Coincidencia entre el lugar de la enunciación y el lugar del enunciado.

Hicimos el cambio de instrumentos/ es decir no es el instrumento sino el trabajo tradicional/ porque antes aquí / cuando la conga salía... 


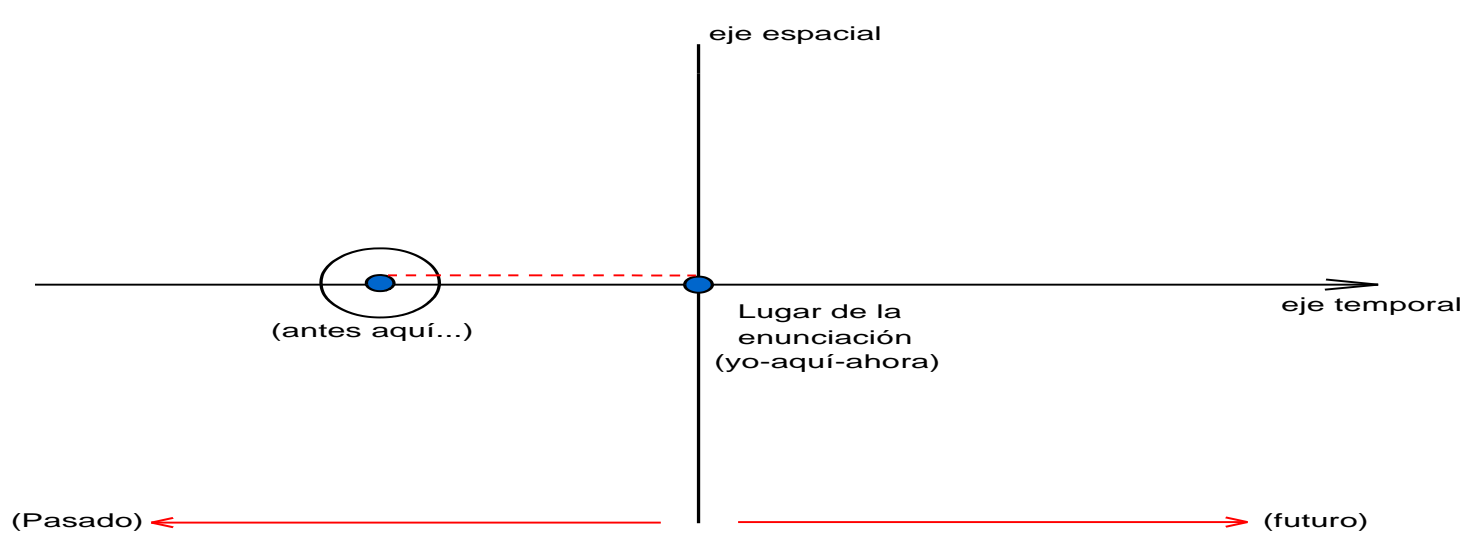

Fuente: Elaboración propia.

Como puede apreciarse, el lugar en el que se desarrolla la historia puede coincidir con el punto en el que se encuentra el emisor en el momento de su producción; los referentes suelen estar visibles, presentes en el contexto físico y en el campo controlado por la percepción sensorial del hablante.

En otros casos, el centro de orientación tiene que ser reconstruido sin apoyo visual, creando así una diferencia entre el espacio del acto comunicativo y el narrado o referido; el enunciador lleva a su interlocutor a una situación recordada a través del uso de los deícticos. Este proceso impone un desplazamiento mental y se basa en las presuposiciones sobre el conocimiento que posee el receptor quien tendrá que situarse en el sistema de coordenadas establecido para el relato, trasladándose, de esta forma, a un espacio que se reconstruye cognitivamente (proyectivo imaginario).

En este sistema de señalamiento los referentes se encuentran ausentes de la situación real del hablante. Este empleo puede graficarse de la siguiente forma (Esquema 3).

Esquema 3. Lugar del enunciado distinto al lugar de la enunciación.

Yo pienso que puede progresar, pienso porque ha cambiado mucho en el sentido del robo/ antes robaban cantidad por allá... 


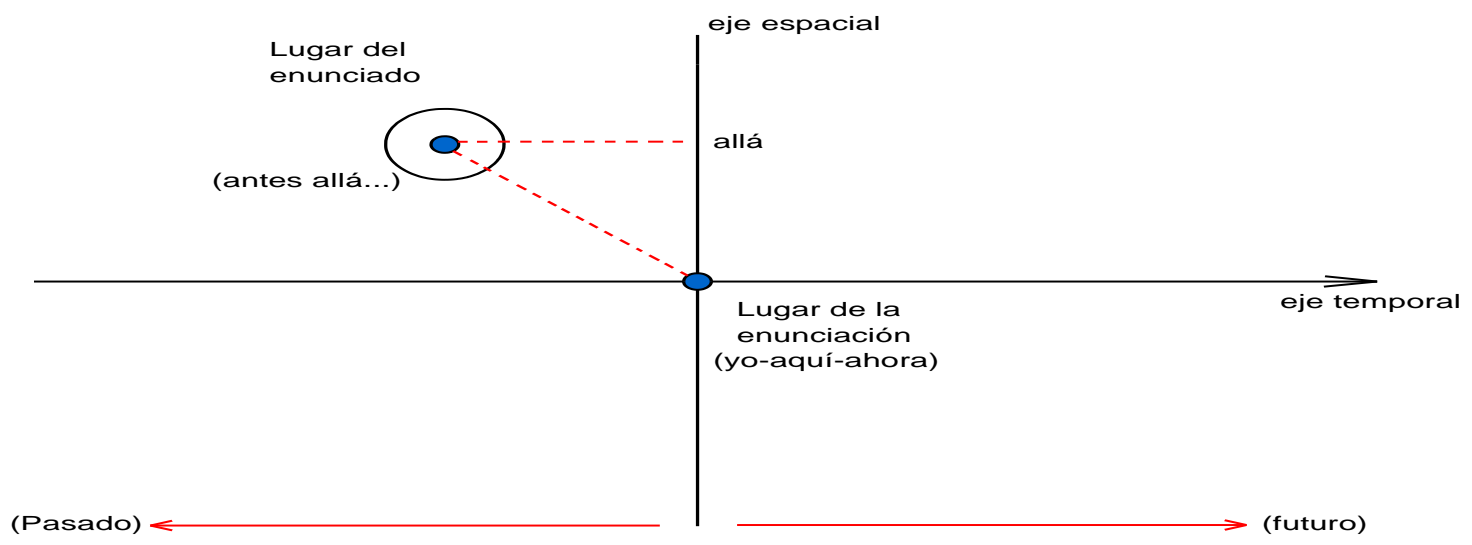

Fuente: Elaboración propia.

Tal y como se ha observado, el relato conversacional es un marco idóneo para que los hablantes puedan establecer, mantener o cambiar las coordenadas espacio- temporales, bien en relación con la propia situación de enunciación o con el contexto extralingüístico del propio discurso. El estudio de las referencias espaciales debe tener en cuenta, por tanto, la presencia o ausencia de lo que se enuncia o se señala, pues ambos son factores determinantes que justifican el proceso de desplazamiento espacial que caracteriza estos textos.

En este plano también debe prestarse atención a la relación que se establece entre el tiempo de la situación que se describe en el texto (tiempo del enunciado) y el punto cero temporal del contexto deíctico en que se produce (tiempo de la enunciación), pues resulta significativa para describir el comportamiento discursivo de la deixis espacial. Cada categoría deíctica construye un espacio mental en el que emisor y receptor están igualmente presentes en un momento determinado. Esta compartida conceptualización del origo supone la perspectiva desde la cual se narran los eventos en relación con la red de relaciones temporales sobre los cuales se organiza.

El tiempo suele ser caracterizado como un sistema de naturaleza deíctica en el que, generalmente, se distinguen tres relaciones principales: anterioridad, simultaneidad y posterioridad, las cuales corresponden a los términos convencionales de pasado, presente y futuro (Cortinas, 2014, p. 241); la deixis temporal gramaticaliza la relación que existe entre el tiempo de los 
eventos referidos y el momento de su enunciación, de manera que se impone estudiar las categorías lingüísticas espaciales en consonancia con el proceso discursivo del cual forman parte.

El eje de la temporalidad es de suma importancia para el análisis de la deixis espacial en relatos conversacionales pues en estos textos se adopta una perspectiva temporal que no se corresponde con el momento de habla (anterioridad). La codificación de las acciones presentadas se realiza tomando siempre como punto de partida el "ahora" en el que se encuentra el hablante y a partir de ese presente se crea un pasado en el que se insertan y ordenan en el espacio los eventos referidos. El tiempo de la situación comunicativa es donde el hablante siempre se sitúa y desde donde mide los acontecimientos que han tenido lugar en el pasado.

Entre el tiempo y el espacio existen diferencias que en la lengua se traducen, por una parte, en la asunción de que el ahora, centro de orientación temporal, es, a diferencia del aquí, idéntico para los participantes en el acto de habla; por otro lado, la naturaleza unidimensional del tiempo, frente a la multidimensional del espacio, se manifiesta desde el punto de vista lingüístico como el área discontinua en la que los momentos del pasado se delimitan por referencia al instante presente, lo que explica el estrecho paralelismo entre los recursos de indicación local y temporal utilizados en estos textos.

El manejo funcional de la deixis en los relatos permite, por ejemplo, clarificar determinados aspectos situacionales relacionados con la información contenida en el texto; el hablante puede verificar la calidad de su comprensión al realizar una vuelta al momento enunciativo, que supone la adopción de una posición egocentrada. El siguiente esquema muestra ese tipo de señalización en una interrupción temporal producida en el nudo (Esquema 4).

Esquema 4. Señalización espacial producida en una interrupción temporal.

El general Moncada se disfraza y se mete dentro de la conga/¿tú sabes que eso queda allí en Martí y Moncada no?.... 


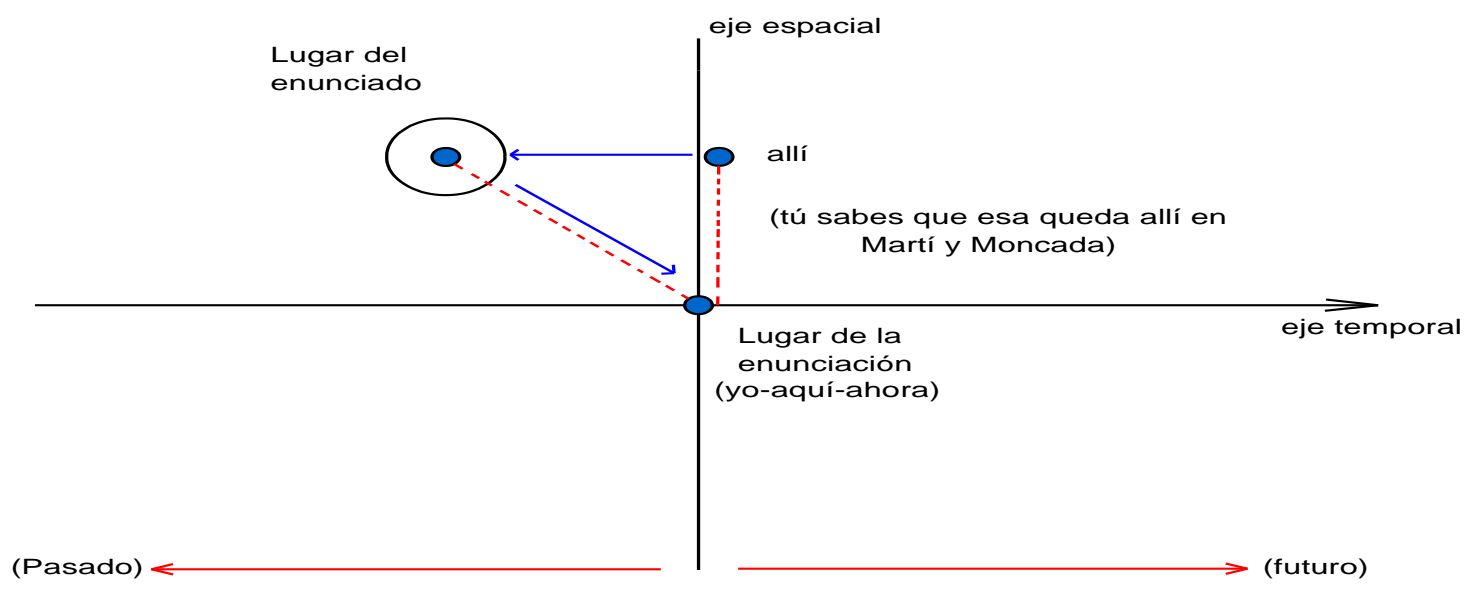

Fuente: Elaboración propia.

En otros casos se produce una transición temporal y temática del tiempo de lo narrado al instante de su producción (ahora), situación típica de la resolución o situación final del relato; en tal circunstancia las informaciones sobre el área de identificabilidad del referente se interpretan desde el lugar y el presente de la enunciación. Este momento discursivo puede esquematizarse como sigue (Fragmento de conversación y Esquema 5).

\section{Fragmento de conversación:}

Fui para Villa Clara/ hice amistades allá y las traía acá/ para que visitaran mi tierra/ para que vieran la parte oriental de nuestro país y ahora aquí estoy/ trabajando/ luchando y ayudando de una forma u otra con un granito de arena a mi Revolución... 
Esquema 5. Transición temporal producida en la resolución o situación final

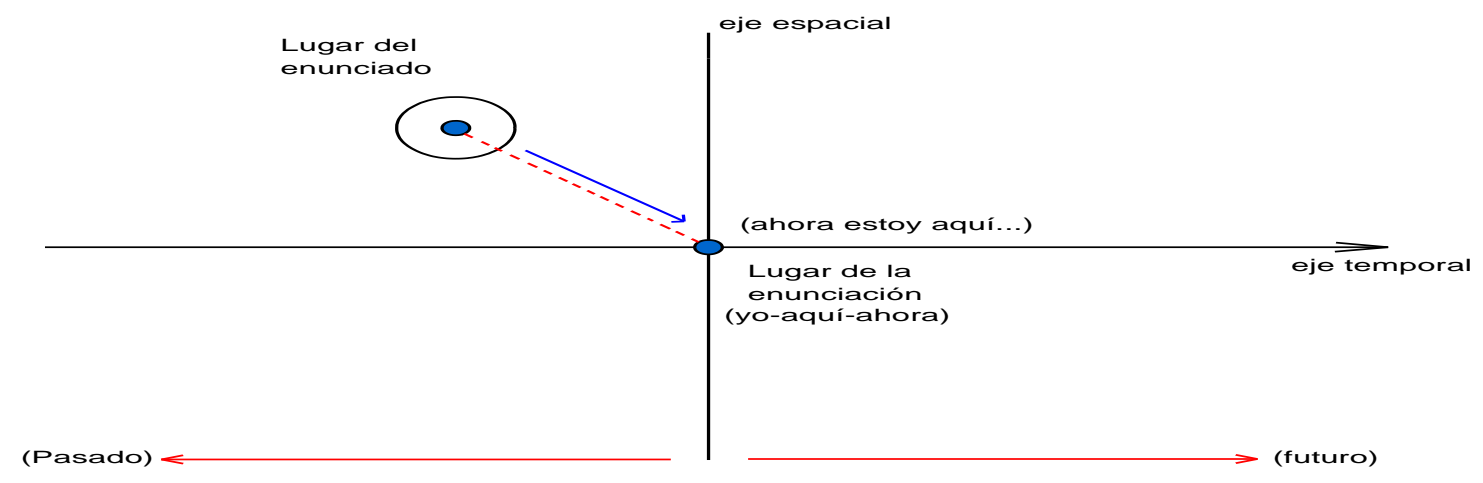

Fuente: Elaboración propia.

Existen, sin embargo, ocasiones en las que los deícticos espaciales contenidos en esta parte se relacionan con las coordenadas establecidas para la historia y no con el punto básico de referencia del hablante (hoy, allá). La situación antes descrita se ejemplifica de la siguiente manera (Fragmento de conversación y Esquema 6).

\section{Fragmento de conversación}

Luego lo trasladó a la fábrica de cemento/ donde lo sepultó bajo este material // hoy la tumba de Felipe Veranes se encuentra allá en el cementerio Santa Ifigenia/ donde están colocadas dos banderas// la bandera cubana y la del 26 de Julio...

Esquema 6. Señalización espacial producida en la resolución o situación final. 


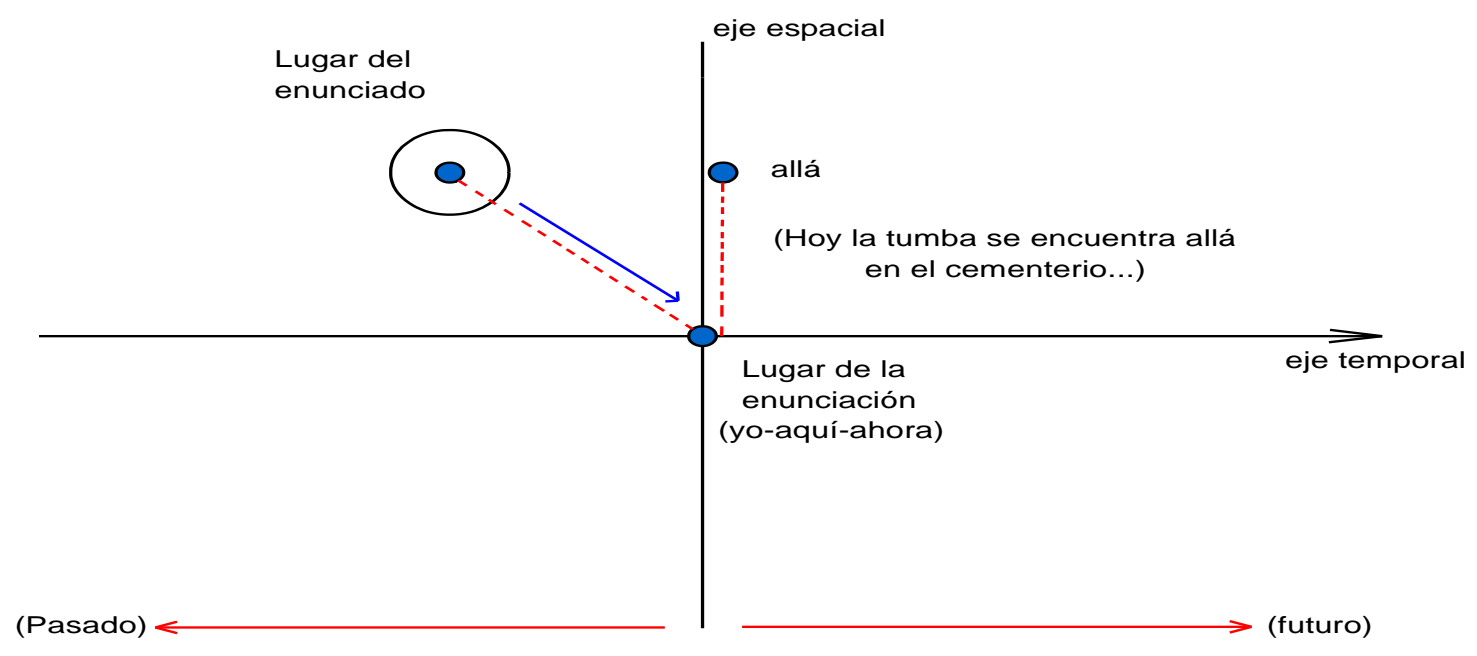

Fuente: Elaboración propia.

En la evaluación, por el contrario, el punto básico de referencia siempre será el eje de coordenadas de la enunciación, pues la función de esta parte es indicar el valor o pertinencia del relato contado en cuanto al tópico de la conversación en general; en su marco resulta frecuente que los hablantes incluyan valoraciones personales sobre los sucesos contados. Tal circunstancia se puede graficar de esta forma (Fragmento de conversación y Esquema 7).

\section{Fragmento de conversación:}

Yo no estoy en contra de los carnavales/ al contrario/ pero deben de seleccionarse calles determinadas/ que no sea esta Avenida de Céspedes que al pasar el carnaval parece que ha pasado por ahí una manada de elefantes/ que trae como consecuencia que desde principio de agosto a junio/ uno se pasa cultivando aquí las plantas y pintando las calles/ y en el mes de agosto se destrozan/ para volver a hacer lo mismo de nuevo/ y eso es lamentable.

Esquema 7. Evaluación de un relato conversacional. 


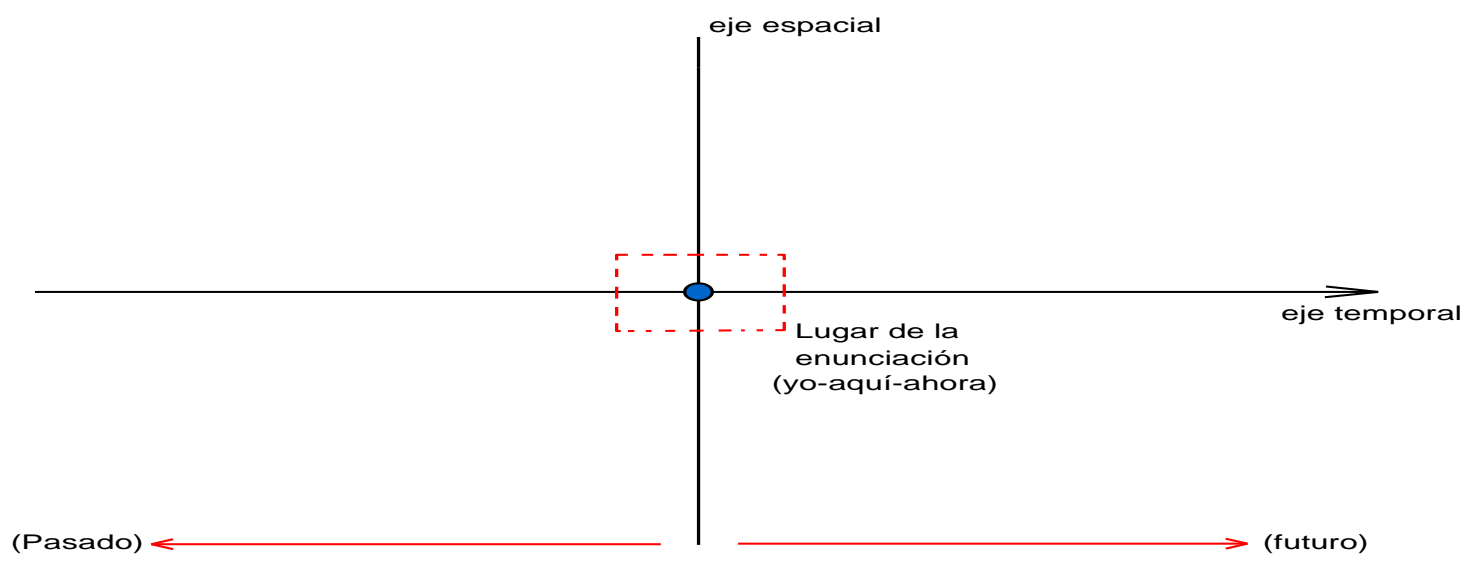

Fuente: Elaboración propia.

El despliegue de relaciones espaciales que permiten la ubicación de los elementos implicados en la enunciación está determinado, como ha sido mostrado, por las características del texto en que se producen, y, en consecuencia, es un aspecto de vital importancia que necesita considerarse en un análisis discursivo.

\subsection{Plano del componente lingüístico: la localización espacial}

Este plano atiende las peculiaridades del fenómeno lingüístico que se analiza pues en cada proceso de enunciación el hablante tendrá que localizar o posicionar las referencias que organizan el universo mostrativo de lo que pretende comunicar; de ahí que estas indicaciones puedan apuntar hacia el contexto extralingüístico o señalar, en otros casos, elementos textuales; de igual forma, resulta imprescindible considerar para la caracterización del comportamiento discursivo de los deícticos, el tipo de localización espacial que se produzca en cada caso.

La utilización de los deícticos en los enunciados permite comprender que, justamente, una de sus funciones es, sin dudas, la de marcar en toda situación de habla el lugar de producción de la palabra. Estas señalizaciones explícitas al emplazamiento físico dan cuenta de la variación que se produce en su empleo de acuerdo con condicionamientos espacio-temporales, los cuales ofrecen 
las razones por las que un hablante elige unas expresiones frente a otras, constreñido, además, por las exigencias del tipo de texto en particular.

La localización espacial debe ser entendida como la construcción de un sistema de referencias que permite situar espacialmente los elementos aludidos en el discurso emitido, relacionando lo expresado con la enunciación lingüística (Benveniste, 1971); por tal razón, resultan relevantes no solo el eje de coordenadas que emisor y receptor deben compartir, sino también la distancia respecto al centro deíctico, los ejes antropocéntricos básicos, entre ellos, la dimensión vertical (arriba-abajo), horizontal (izquierda-derecha), prospectiva o retrospectiva (delante-atrás) y la interior (dentro-fuera), además del tipo de relación espacial que se establece entre los objetos.

La relación locativa estática se establece cuando un objeto se sitúa en el espacio respecto a otro pero no se produce movimiento; la relación dinámica, en cambio, incluye aquellas expresiones que indican un tipo de relación espacial entre dos elementos, delimitándose así un punto de partida y uno de llegada.

Estas localizaciones pueden ser especificadas en relación con la posición y orientación de los participantes (deíctica) u otro objeto de referencia (inherente); por ejemplo, en el enunciado A (el perro está aquí) se infiere que lo indicado se encuentra cerca del campo perceptivo del enunciador, mientras que en B (el libro está encima de la mesa) solo señala la existencia de un objeto con superficie sobre el cual está localizada una entidad.

En otros casos (C), se puede utilizar un segundo punto de orientación relacionado con la posición objetiva del hablante; en tales circunstancias, el enunciador se constituye como el objeto para la descripción espacial y se concibe como una entidad con una disposición intrínseca (él se lastimó aquí, señalando el propio cuerpo). Los anteriores tipos de localización permiten graficarse de la siguiente forma (Esquema 8).

Esquema 8. Tipos de localización espacial. 


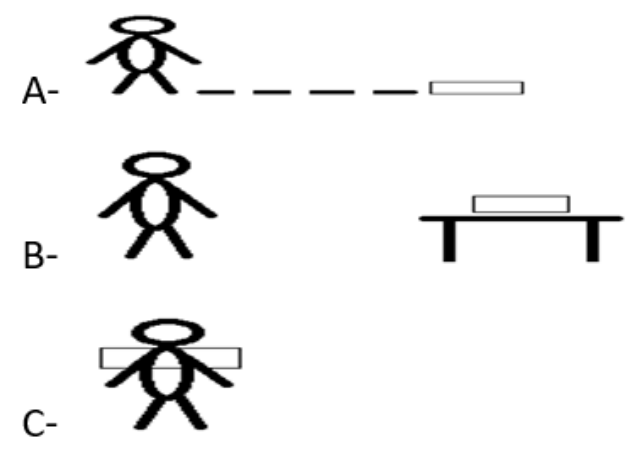

Fuente: Elaboración propia.

En el proceso de localización espacial también resulta frecuente que se pueda instrumentar un cambio de perspectiva en la articulación del sistema deíctico (quien dice "yo" puede simplemente estar citando a alguien que dice "yo" y desde esta posición establecer las coordenadas deícticas) aunque, sin obviar, el papel crucial de la primera persona en la instancia enunciativa.

El sujeto de la enunciación puede aparecer como agente externo a los sucesos narrados o como participante de los hechos que se cuentan (sujeto del enunciado) pues los relatos se presentan siempre referidos a un sujeto que manifiesta expresar sus opiniones, puntos de vista, experiencias o acontecimientos respecto a sí mismo; o bien como hechos y saberes ajenos a quien los enuncia:

-Dicen ellos que son los llamados muertos que ya desde el primer momento del toque y están haciendo esas cosas se suben...

- Esta provincia claro que me gusta y llevo en ella ya muchos años/te cuento/ yo soy de Guantánamo y vine para acá cuando mi hijo tenía diecisiete meses de nacido... (Fragmento de conversación).

En los casos en que el productor del enunciado es protagonista del relato, su relación con la situación de enunciación estará determinada por autorreferencias constantes que favorecen su ubicación dentro del discurso; sin embargo, en aquellas narraciones en las que el locutor está 
ausente y se limita a describir lo que alguien le ha contado, se desplaza el centro deíctico para señalar, de esta forma, que el conocimiento proviene de otras fuentes (evidencia transmitida) y es usado como un argumento de fundamentación. Los referentes, en ambas circunstancias, están en correspondencia con el tema del texto narrativo en que aparecen insertos.

En el discurso referido el eje espacial puede suponer cambios que responden a un desplazamiento o mantenimiento de las localizaciones anteriormente establecidas por otro interlocutor. La diferencia, en cada caso, responde a que el estilo directo conserva los enclaves deícticos del texto de origen (Me dijo: estoy cerca de ahí); el indirecto, por el contrario, no reproduce exactamente el discurso original, sino que requiere la utilización de un enmarque explícito y una transposición de los elementos deícticos para adaptarse al origo (Me dijo que estaba cerca de aquí). Del estilo directo al indirecto hay que efectuar un ajuste deíctico que tiene como punto de referencia al yo hablante intencional; una cosa es el sujeto empírico, responsable de la enunciación y otra es el ser del discurso como una ficción discursiva.

En el análisis que se propone, los deícticos son concebidos, por otro lado, como "indicios de contextualización" que pueden aludir, tanto al cotexto (remisión a elementos del enunciado o intratextuales), como al contexto (elementos del acto de la enunciación o extratextuales) para crear un texto íntegro que permite guiar al receptor en su interpretación.

Lo anterior conduce, entonces, a reconocer el relato conversacional en un estudio de esta naturaleza, como parte integrante del contexto de enunciación y, como tal, puede hacer referencia a sí mismo. El espacio perceptivo es un modelo icónico para el espacio del discurso en el que los deícticos apuntan hacia un elemento textual del mismo modo que en una situación real, señalan a un objeto del mundo.

La diferencia entre un tipo de localización u otra (textual o situacional) no difiere más que en el espacio deíctico que involucra. En ambos casos, la atención se dirige hacia la realidad, señalando elementos del contexto extralingüístico o aludiendo, en otros casos, a información que ya ha aparecido (anáfora) o se encontrará de manera posterior (catáfora).

Desde niña me fui a vivir con mis abuelos y pasé toda mi juventud por allá... ( $\leftarrow$ allá) 
Todo el mundo no tiene las mismas oportunidades en la vida/ yo no tuve la posibilidad de estudiar/ te cuento/ allá yo estudié hasta el sexto grado/ de ahí empecé a trabajar/ muy joven en ese pueblito donde nacieron mis padres.... (allá $\rightarrow$ ) (Fragmento de conversación).

Los anteriores elementos resultan esenciales para que una localización espacial pueda reconocerse

e interpretarse de modo unívoco, al menos funcionalmente hablando. En el plano discursivo, sin embargo, existen ocasiones en las que las coordenadas y dimensiones de las nociones de lugar no son codificadas de forma deíctica (las estructuras metafóricas con ausencia de los rasgos locativos prototípicos constituyen un ejemplo); la manera en que se configura cada enunciado, por tanto, sirve de guía para su interpretación al incorporar otros aspectos entre los que se encuentran, por ejemplo, las intenciones del productor del texto.

El comportamiento discursivo de los deícticos espaciales, como se ha observado, está relacionado con varios aspectos que permiten mostrar la relación entre la estructura textual y los elementos de la situación comunicativa sistemáticamente ligados a ella.

\section{3 Plano del componente pragmático: la adecuación contextual del significado}

El tercer plano tiene en cuenta, por su parte, que los enunciados son emitidos, no solo para transmitir un significado referencial (en el caso de los deícticos) sino que al hacerlo, el hablante responde a una intención; razón que haya hecho considerar a la deixis (Escavy, 2008) como la principal manifestación pragmática del sujeto que razona intencionalmente.

El contexto, y con ello los factores contextuales, constituyen, entonces, conceptos cruciales y definitorios del ámbito de la pragmática y el análisis del discurso, pues su consideración en la descripción de los usos lingüísticos marcará la línea divisoria entre los estudios discursivos y los meramente gramaticales (Casalmiglia y Tusón, 1999, p. 108).

El estudio de la deixis, como antes se ha apuntado, permite distinguir cómo se inscriben en los enunciados los parámetros referentes al contexto enunciativo, los cuales dan cuenta de la existencia de principios generales en el uso del lenguaje, pues justamente son los deícticos quienes 
más claramente expresan el principio de determinación contextual de la significación; por consiguiente, se hace necesario, para el análisis de los locativos espaciales, una lectura pragmática que considere las condiciones que determinan tanto el empleo de un enunciado por un hablante en una situación comunicativa concreta como su interpretación por parte del destinatario.

Los relatos, por su parte, son actos comunicativos que suponen la existencia de un emisor con una intención (¿’por qué narrar?) y una finalidad (¿para qué narrar?), de esta forma, estos textos surgen al hilo de la conversación y son activados en la memoria para explicar con mayor profundidad algún aspecto relacionado con el tema propuesto, favoreciendo una intervención más espontánea, natural y menos sujeta al control por parte del hablante, además de cumplir una función pragmática con un interés determinado (informativo, ejemplificativo, argumentativo); de acuerdo con esto, los relatos conversacionales poseen una carga ilocutiva e intencional significativa, de manera que los elementos deícticos sustentados en las coordenadas contextuales hacen que el mensaje cobre sentido ante el oyente.

A pesar de que el contexto no está determinado por el emisor, este puede condicionarlo de alguna forma y proyectar una situación que logre ser comprendida de forma satisfactoria por el otro; en este sentido, es el destinatario el que tiene que asumir la contextualización de la emisión lingüística en cuestión, tratando de reconstruir el entorno óptimo para su interpretación; se hace necesario, por un lado, reconocer su papel en la interpretación como un límite al conjunto de posibles interpretaciones y, por otro, como un apoyo para la interpretación pretendida (González, 2007, p. 80).

Este plano permite dirigir la atención hacia el hecho de que toda expresión deíctica empleada lleva implícita, además, una intencionalidad del sujeto, lo que equivale a reconocer que la construcción del significado no solo está ligada al establecimiento de las coordenadas espaciotemporales de la enunciación; conocer e interpretar las claves extralingüísticas que les permiten a los hablantes señalar en el espacio y relatar acontecimientos alejados del contexto inmediato en que ocurre la enunciación, revelan las funciones pragmáticas que se derivan de un estudio de esta naturaleza. 
La reiteración de los deícticos espaciales en los relatos, por ejemplo, puede tener intenciones comunicativas muy diversas, entre ellas la de contribuir a la cohesión narrativa y a la intensificación de la fuerza ilocutiva del enunciado; las ocurrencias de deícticos dobles, por su parte, destacan y enfatizan las circunstancias de producción del discurso combinando espacio y tiempo; los marcadores discursivos contribuyen al procesamiento de lo que se comunica por lo que pueden usarse como guías u orientadores de la actividad interpretativa que se desencadena a partir del empleo de estas expresiones referenciales.

Como bien se ha observado, la deixis no solo proporciona las coordenadas espaciotemporales del discurso, sino también las coordenadas pragmáticas de la enunciación que vienen dadas, entre otras, por las intenciones del hablante, el oyente y la situación comunicativa; los anteriores aspectos permiten mostrar la relación entre los diferentes elementos lingüísticos que configuran el texto y el contexto en que es utilizado; precisamente es desde esa óptica que debe valorarse y describirse la emergencia discursiva de los deícticos en este tipo de texto.

Los planos antes expuestos están dotados de capacidad descriptivo-explicativa adecuada para caracterizar el comportamiento de la deixis espacial en relatos conversacionales. El siguiente esquema resume los aspectos tratados en las páginas anteriores (Esquema 9). 
Esquema 9. Resumen de los planos que permiten describir el comportamiento discursivo de la deixis espacial en relatos conversacionales.

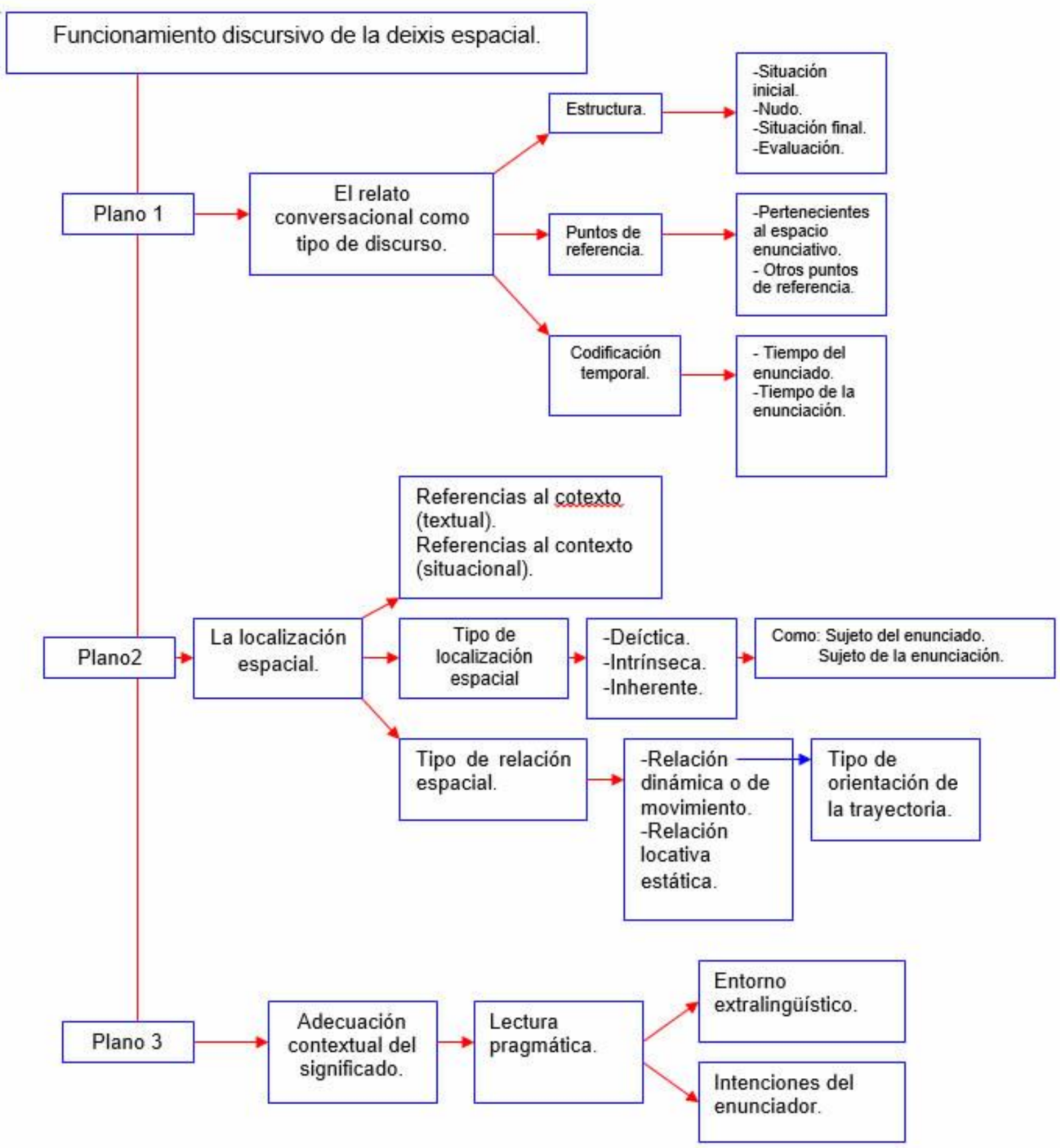

Fuente: Elaboración propia. 


\section{Conclusiones}

Un estudio de la deixis espacial en relatos conversacionales debe adoptar necesariamente un enfoque que permita disponer de un corpus que sea resultado del uso real de las expresiones lingüísticas en un contexto definible y con un propósito determinado. Esta formulación ha de considerar, por otra parte, el rol del destinatario pues todo proceso discursivo se desarrolla a partir de las informaciones aportadas por el enunciador sobre el proceso mismo (los deícticos), las cuales se convierten, a la vez, en indicios que el receptor debe asumir para la adecuada interpretación de los enunciados.

Los instrumentos de análisis planteados ofrecen criterios que orientan un estudio lingüístico de esta naturaleza y resultan válidos para la descripción de su comportamiento discursivo en el tipo de texto analizado. Su estructuración en planos posibilita la realización de un estudio más puntual que tome en cuenta las peculiaridades del tipo de texto analizado, para el análisis del fenómeno lingüístico observado, y su adecuación a la situación comunicativa concreta.

\section{Referencias}

Arnás, I.; y Fumero, M. (2007). Marcadores de conexión: los conectores. Recuperado de https://www.researchgate.net/publication/238730727 Marcadores de conexion los cone ctores

Calsamiglia, B, H. y Tusón, V. A. (1999). Las cosas del decir. Manual de análisis del discurso. Barcelona, Editorial Ariel. Recuperado de https://universitas82.files.wordpress.com/2013/08/las-cosas-del-decir.pdf Castillo, M.; y Camacho, C. (2007). El uso de elementos indexicales en los textos narrativos orales sobre botijas y espíritus en la comunidad de Valle Guanape, Edo. Anzoátegui, Recuperado de http://www. http://190.169.28.5/tesis/faces/TESIS\%20E2007\%20C352/tesis.pdf.

Cifuentes, J.L. (1986). Lengua y espacio. Introducción al problema de la deixis en español. Alicante, Universidad de Alicante. 
Cortinas, S. (2014). Deixis y referencia en el habla infantil. Presentadores espaciales y temporales en el corpus Koiné. Tesis presentada en opción al grado científico de Doctor en Ciencias lingüísticas. Universidad de Santiago de Compostela.

Escavy, R. (2008). Pragmática y subjetividad lingüística. Murcia, Ediciones de la Universidad de Murcia.

Eguren, L. J. (2000): Pronombres y adverbios demostrativos. Las relaciones deícticas, en Bosque, Ignacio y Violeta Demonte (dir.) (2000), Gramática descriptiva de la lengua española. Vol.1. Madrid, Editorial Espasa Calpe.

Fillmore, C.J. (1975).Lectures on Deixis. Bloomington, Indiana University Linguistics Club.

García-Azkoaga, I. M. (2010): Cohesión en situación de interacción: el caso de la narración oral. Recuperado de http: www.clunl.edu.pt/resources/docs/.../5m\%20ines\%20azkoaga.pdf.

Gallardo, B. (1996). Análisis conversacional y pragmática del receptor. Recueprado de http: www.elvira.Illf.uam.es/clg8/actas/pdf/paperCLG31.pdf.

González, M. (2007). Claves para la actualidad de la hermenéutica. Tesis presentada en opción al grado científico de Doctor en Ciencias. Facultad de Filosofía. Tutora DrC. Concha Roldán Panadero. Universidad Complutense de Madrid.

Gutiérrez, S. (2001). Acción, relato, discurso: Estructura de la ficción narrativa, Recuperado de http: www.es.scribd.com/doc/.../Las-Narraciones-Como-Recurso-Argumentativo

Hipogrosso, C. (2001). El campo mostrativo del lenguaje: una introducción al comportamiento de los pronombres. Recuperado de http://materialeshipo.blogspot.com/2006/12/el-campomostrativo-del-lenguaje.html

Labov, W. (1972). The Transformation of Experience in Narrative Syntax en: Language in the Inner City: Studies in the Black English Vernacular. USA, University of Pennsylvania Press

Portolés, J. (s.f.). Pragmática y sintaxis, Recuperado de https://webs.ucm.es/info/circulo/no16/portoles.htm 
Real Academia Española (2009). Nueva gramática de la lengua española, Asociación de academias de la lengua española. España, Editorial Espasa Libros. Recuperado de http://www.rae.es/sites/default/files/Sala prensa Dosier Gramatica 2009.pdf

Shiro, M. (1999). Echar el cuento: hacia un perfil de las destrezas narrativas orales en niños caraqueños. Recuperado de http://www.um.es/tonosdigital

Stanzel, F. K. (1978). La mediación narrativa. Recuperado de https://www.academia.edu/17475602/La mediacion narrativa 